\title{
Simulation Study of Dynamic Response of Bolt Support in Impact Roadway
}

\author{
Liu Fan ${ }^{1,2}$ Liu Wenjie ${ }^{1}$ Wang Tongxu ${ }^{1}$
}

${ }^{1}$ College of Mining and Safety Engineering, Shandong University of Science and Technology, Qingdao 266590, Shandong, China

${ }^{2}$ Coal Industry Bureau of Shandong Province, Jinan 250031, Shandong, China

\begin{abstract}
Coal burst and mine earthquake frequently occur with high strength in impact roadway. Bolting system will produce a certain dynamic response under the impact load disturbance. Bolts will be damaged and rock will be instability when it serious. How to design bolting system in impact roadway is a major technical problem that has not been solved. This paper analyzes the dynamic response of bolt supporting in impact and mechanized caving roadway by FLAC3D. Then it gets the bolt axial force, shear stress of anchor agent and deformation of roadway variation with time and space. This study provides the design basis for the optimizing impact roadway bolting and improves control effect of bolting system. The results show that under the impact load the degree of dynamic response of anchor and roadway has great relationship with the distance between the measuring point and the power source. It reflects sensitively. Tilt bolts affect greatly. Threads and components of bolt tail are easily damaged, while anchoring agent prone to
\end{abstract}

shear failure. Therefore, the bolt of rock burst roadway should have high prestress and high strength. While the choice of bolt end member, anchoring agent, the let press member and bolt elongation with high energy absorption properties are also very important.

Keywords: impact load, mechanized caving roadway, bolt support, dynamic response, numerical simulation.

\section{Introduction}

With the increasing depth of coal mining, rock burst occurred more frequently. Many rock burst occurred in the roadway of driving and mining. Therefore, to enhance the impact roadway supporting is attracted people's attention much more. As to the problem of rock burst roadway supporting, many scholars have conducted extensive research and achieved some results. Pan Yishan and Lv Xiangfeng ${ }^{[1-2]}$ analyzed the mechanism of impact energy absorbed by the coupling support, and proposed the method of energy-absorbing coupling support. They provided a new method for the support of impact roadway. Gao Mingshi ${ }^{[3-4]}$ established and analyzed a 
strong-soft-strong (3S) structural model to prevent rock burst from taking place. At last, several techniques such as decreasing shock energy, setting proper soft structure, and improving support strength were put forward to prevent roadway from being destructed by rock burst. Ju Wenjun ${ }^{[5]}$ proposed the energy check design method for rock burst roadway which is based on energy theory of rock burst. This method is by calculating the energy absorption index of bolting components for anti-scour design. Wang Ping and Jiang Fuxing ${ }^{[6]}$ provided the experimental design method under different impact conditions and on the base of experimental research of the large deformation of bolt (anchor cable). It analyzes the dynamic response of bolt support in impact and mechanized caving roadway by FLAC3D.Then it gets the bolt axial force, shear stress of anchor agent and deformation of roadway variation with time and space. This study provides the design basis for impact roadway bolting and improves the stability of roadway under impact load.

\section{Simulation model}

The depth of numerical simulation roadway is $800 \mathrm{~m}$. The Seam dip is 13 - The Seam thickness is $17 \mathrm{~m}$. Mechanized caving roadway designs along the bottom. The Diameter of semiarched roadway is $4.0 \mathrm{~m}$ and the high wall is $2.0 \mathrm{~m}$. Model size is $50 \mathrm{~m} \times 15 \mathrm{~m} \times 60 \mathrm{~m}$. Numerical model selects Mohr Coulomb model. The initial stress field is generated by the weight of overlying rock. The support method of roadway is bolt support. The impact load is located at one side of roadway about 2 times the roadway width. 1 11said bolt (Cable) number, $\mathrm{a} \sim \mathrm{h}$ show the measuring point of roadway surface displacement, (1) (3) are free sections and (4) is anchoring section of anchor in Figure 1.

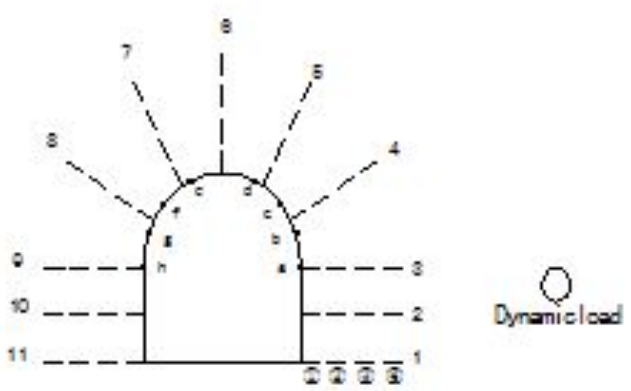

Fig.1 bolting system and impact load position

1) impact load

Impact load function:

$$
p(t)=\left\{\begin{array}{l}
0, \quad t<0 \\
3.2 \times 10^{9} \exp (-427.5 \times \mathrm{t}), \quad \mathrm{t} \geq 0
\end{array}\right.
$$

Where $p$ and $t$ is impact load and impact time, unit is $P a$ and $s$.

2) boundary conditions

The Dynamic analysis adopts the flexible model-based. Top bottom and four sides of model imposed static boundary conditions. It is the viscous fluid boundary too. It is to simulate nonreflective boundary of infinite medium by connecting boundary normal and tangential damper. The tensile of shearing and normal direction provided by damper are computed according to formula (2) and (3).

$t_{n}=-\rho C_{p} v_{n}$

$t_{s}=-\rho C_{s} v_{s}$

Where $t_{n}$ and $t_{s}$ is normal tensile stress and tangential stress, $v_{n}$ and $v_{s}$ is normal and tangential velocity component, $\rho$ is 
medium density, $C_{p}$ and $C_{s}$ is $p$ wave velocity and $s$ wave velocity.

3 ) selection of the damping

FLAC3D dynamic analysis module provides a variety of damping in the forms of Rayleigh damping, Local and Artificial viscous damping, etc. In this paper, bolt choices Local damping and takes the critical damping ratio of $8 \%$.Coal and rock materials use artificial viscous damping.

4) Model size

To accurately simulate wave propagation in the model, the model cell size required to satisfy (4).

$$
\Delta l \leq \lambda / 10
$$

Where $\Delta l$ is model grid cell size, $\lambda$ is the highest frequency component wavelengths with primary energy.

Simulation process: first, it generated the initial stress field and excavates roadway, then conducted bolting under FLAC3D static analysis module and calculated to balances; second it transformed into dynamic analysis module to simulate the influence of the roadway and bolt by impact load. Coal rock parameters and bolt parameters are shown in Table 1 and Table 2.

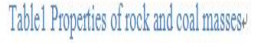

\begin{tabular}{|c|c|c|c|c|c|c|}
\hline Lithologyp & bullamodulus G? & shent & ammodus $\mathrm{CP}_{2}$ & colesion $M \mathbb{P}_{2}$ & tension $\mathbb{M p p}_{\mathrm{p}}$ & av firction" \\
\hline gandstoner & $30.3+$ & & 21.2 & 19 & 211 & 36 \\
\hline \multirow[t]{2}{*}{$\mathrm{cads}$} & 0.8 & & 0.9 & 0.58 & 0.5 & 27 \\
\hline & \multicolumn{6}{|c|}{ 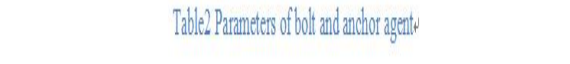 } \\
\hline $\begin{array}{l}\text { bolt denisty } \\
\text { log mit? }\end{array}$ & bolt & $\begin{array}{l}\text { boltedasicic } \\
\text { modulus } \\
\text { Gpp }\end{array}$ & $\begin{array}{l}\text { bol yided } \\
\text { strenght } \\
\mathbb{K}:\end{array}$ & $\begin{array}{c}\text { andhor gaget } \\
\text { stifferess } \\
\text { GPpa }\end{array}$ & 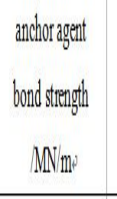 & 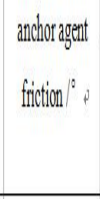 \\
\hline 9850 & $0.0 \%$ & 20 & 348 & 9.0 & 20 & 35 \\
\hline
\end{tabular}

\section{Simulation results analysis}

\subsection{Dynamic response of bolt axial force}

Changes of the axial force of bolt elements with time show in Figure 2. Among them, Figure 2 (a) represents the third free section unit of bolt, Figure 2 (b) represents the anchoring section unit.

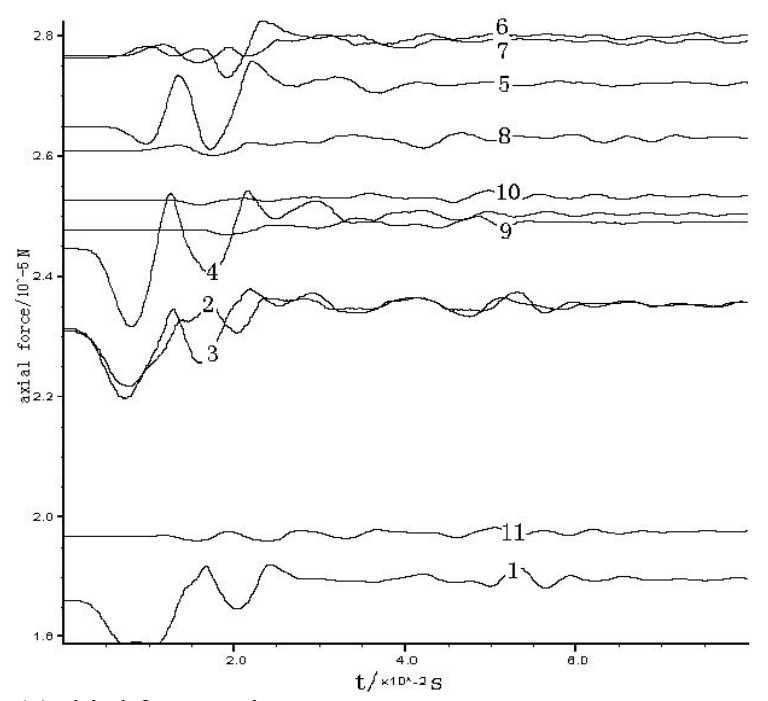

(a) third free section

Figure 2 and 3 show that the changes of axial force of bolt with different mounting positions are different under the 
impact load. The bolt axial force changes larger before $0.02 \mathrm{~s} \sim 003 \mathrm{~s}$, then stabilized. Bolt has small force at the bottom but it has large force at the top of mechanized caving roadway. Close to the power source 1 to the 5 th bolt under load is larger while

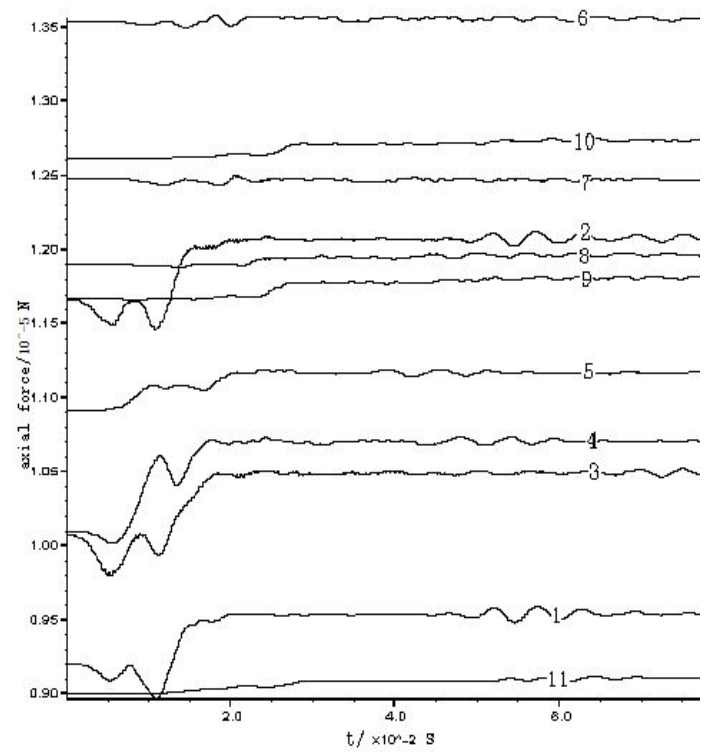

(b) anchoring section

Fig. 2 Changes of the axial force of bolt elements with time

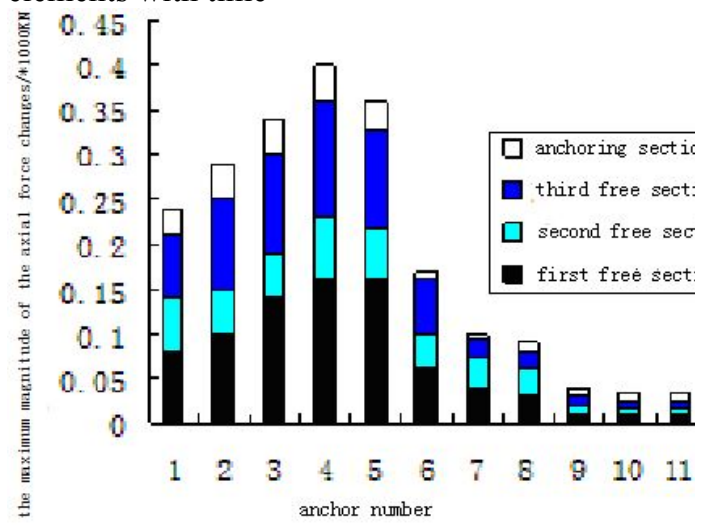

Fig.3 Differential charts of axial force of bolt elements

far away from the power source 7 to 11 set by a smaller bolt. On a single anchor, the pull of free section near bolt tail and anchoring agent is large, while the pull of second free section and anchoring agent is small. The former is about 2.0 times of the latter. Axial force of tilting bolt is larger.

\subsection{Dynamic response of anchoring agent shear stress}

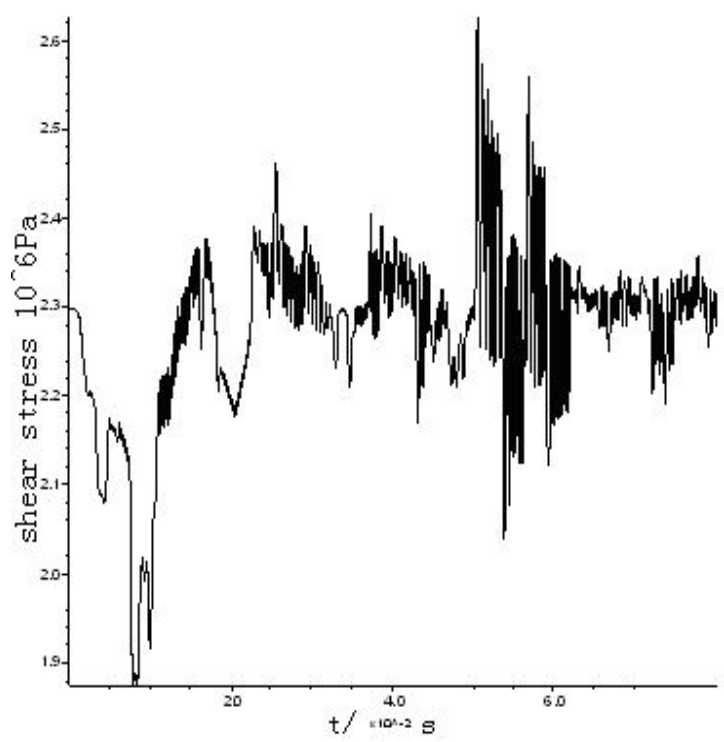

(a) anchor agent of $1 \#$ bolt

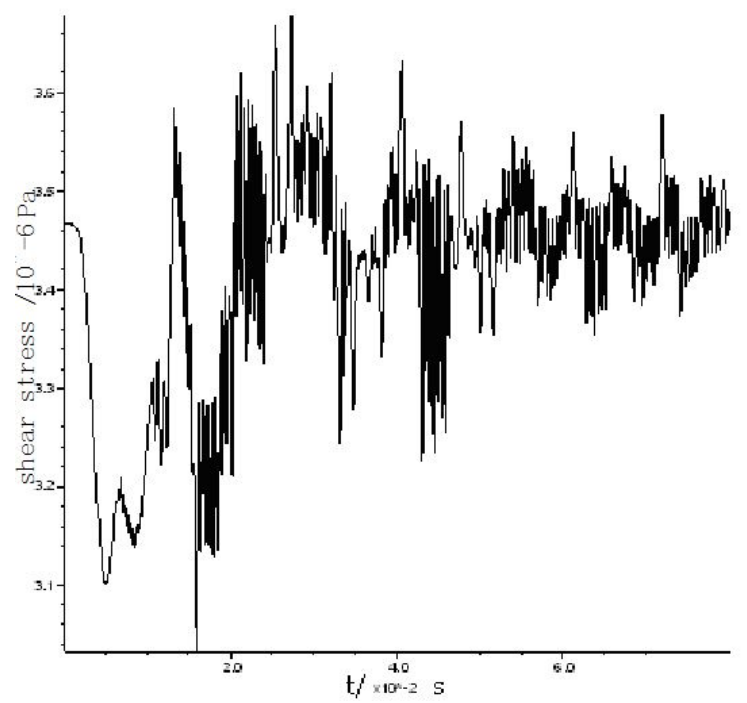

(b) anchor agent of $4 \#$ bolt

Fig.4 Changes of shear stress of bolt grouts with time

It can be seen from Figure 4, that the vibration frequency of anchoring agent shear stress is high. Vibration amplitude is great. In addition, the first pulse anchoring agent suffered downward. It consists with the direction of the first 
pulse anchoring section suffered. The influence time of anchoring agent by power disturbances is longer. But with the increasing distance from the power source, the vibration frequency quickly attenuates. So anchoring agent is also a weak link under the dynamic disturbance.

\subsection{Dynamic response of roadway}

Figure 5 is the effect of the displacement of roadway when disturbed.

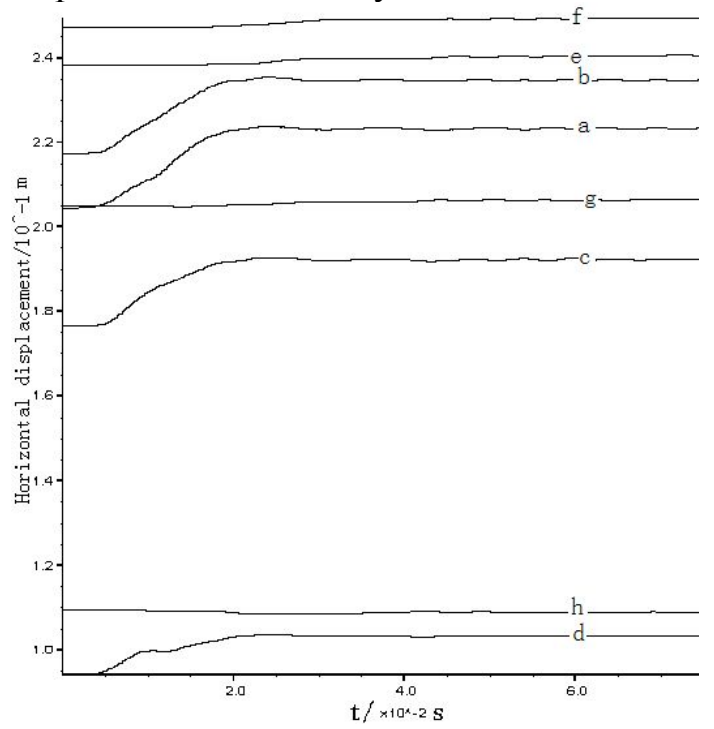

Fig.5 Changes of horizontal displacement of survey points with time on the wall

Figure 5 shows that the horizontal displacement of $\mathrm{a} \sim \mathrm{d}$ measurement points near the power source increase monotonically, and the biggest increase is $11.3 \%$. While the horizontal displacement of $\mathrm{e} \sim \mathrm{h}$ measuring points far from power source is smaller. In time, the horizontal displacement of roadway stabilizes after $0.02 \mathrm{~s}$.

\section{Conclusions and application analysis}

It analysis the dynamic response of blot under impact force by numerical simulation, and the conclusions can be drawn as following:

1) The bolt supporting for impact load in the impact roadway, The axial force of free section changes relatively greatly approaching to the end and anchorage section, the axial force of anchorage section shows little changes, which shows that the end of bolt is greatly influenced by the dynamic disturbance, anchor agent can weakens vibration of rod body by dynamic load.

The end of bolt and anchor agent are the weak links of dynamic load disturbance; the former easily occurs tensile failure, the latter easily lead to shear failure, so the effect of impact load should be considered for the design for thread and nut of the bolt's end, pallet, steel beam and anchor agent etc.. The end parts share impact load by transmission of axial force of anchor bolt, the range of resistance to impact is expanded. The anchor agent should absorb impact load effectively, lessen the impact influence of anchoring section and prevent shear failure of anchoring section.

2 ) Under the action of impact load, the displacement and the delay time of roof and sides are different. The parameters should be selected differently which the elongation and let press component preventing impact bolt by the displacement. Only in this way, the bolt support can work effectively. In this paper, the displacement of roof and the inclined bolt is large, so the parameters should be increased moderately.

3 ) The support forms includes impact energy-absorbing coupling support, let press bolt support, large deformation and high strength support, anti-impact strongsoft-strong structure support , etc. Appropriate surplus coefficient and let press ability are necessary in the support of rock burst roadway.

The results show that it's also very important to select the appropriate the bolt end parts, anchor agent, letting press structure and bolt elongation when the bolt have ability of high prestress and strength in rock burst roadway. 


\section{References}

[1]Pan Yishan,Lv Xiangfeng,Li Zhonghua, "The model of energyabsorbing coupling support and its application in rock burst roadway,"[J].Journal of Mining \& Safety Engineering, Vol28,NO.1Pp:610,2011.

[2]Lv Xiangfeng,Pan Yishan,"Simulation and numerical analysis of impact failure law of coal roadway under rigid-flexible energy absorbing support," $[\mathrm{J}]$. Chinese Journal of Geotechnical Engineering, Vol34,NO.3

Pp:477-482, 2012.

[3]Gao Mingshi,Dou Linming,Zhang Nong,et al. "Strong-soft-strong mechanical model for controlling roadway surroundingrock subjected to rock burst and its application,'[J]. Rock and Soil Mechanics, Vol29,NO.2, Pp:359-364, 2008.
[4]Gao Mingshi,Dou Linming, Yan Ruling, et al. "Prevention mechanism of roadway supported by bolt-mesh subjected to rock burst and degree calculation," [J].Journal of Mining \& Safety Engineering, Vol26, NO.4,Pp:402-404,2009.

[5]Ju Wenjun, "Energy checking design method of roadway with rock burst danger," $[\mathrm{J}]$. Coalmining Technology,Vol16, NO.3, Pp:8183,2011.

[6]Wang Ping,Jiang Fuxing, Wang Cunwen, et al. "The study on coordination for avoiding impact using bolt and anchor cable with large deformation,"[J].Journal of Mining \& Safety Engineering, Vol29,NO.2, Pp:191196,2012 